\title{
Low-Power Printed Circuit Board Fluxgate Sensor
}

\author{
Jan Kubík, Lukáš Pavel, Pavel Ripka, Member, IEEE, and Petr Kašpar
}

\begin{abstract}
A new printed circuit board flat fluxgate sensor with integrated coils and amorphous alloy core was developed and its excitation parameters optimized for low-power consumption. The power consumption achieved with $10 \mathrm{kHz}, 300 \mathrm{~mA}$ p-p pulse excitation with duty cycle $12.5 \%$ was only $3.9 \mathrm{~mW}$, which is three times lower than that for sinewave $B$ excitation. The sensor sensitivity reached $94 \mathrm{~V} / \mathrm{T}$. The required excitation bridge supply voltage was only $0.47 \mathrm{~V}$. The low-cost low-power sensor has a temperature offset stability of $120 \mathrm{nT}$ in the -20 to $+70^{\circ} \mathrm{C}$ temperature range and $0.17 \% /{ }^{\circ} \mathrm{C}$ open-loop sensitivity tempco due to the use of a new core embedding technique. The perming error due to $10 \mathrm{mT}$ field shock was suppressed below $1.2 \mu \mathrm{T}$. The short-time offset stability was $38 \mathrm{nT}$ within $3 \mathrm{~h}$. Thus the developed sensor is more precise and less energy consuming than a periodically flipped anisotropic magnetoresistance (AMR) sensor. The achieved parameters are sufficient for compass with $0.1^{\circ}$ error.
\end{abstract}

Index Terms-Fluxgate sensor, low power, printed circuit board (PCB).

\section{INTRODUCTION}

$\mathbf{C}$ LASSICAL fluxgates with wire wound coils are expensive and bulky. Recent efforts to minimize production costs and decrease the sensor size resulted in use of printed circuit board (PCB) technology [1], [2] or planar microtechnology [3]. All above-mentioned sensors use electroplating or electrodeposition of core material. The quality (permeability, coercive force) of such materials does not meet the qualities of soft rapidly quenched tapes of amorphous alloys. The wet-etched amorphous alloy core was used to create a new type of PCB fluxgate sensor [4].

The miniaturized fluxgate sensors require a new type of lowpower excitation, as classical excitation tuning cannot be used due to the high resistance of the excitation coil and thus low Q-factor of the excitation tank circuit. Excitation by short pulses to reduce the power consumption was already used for fluxgate sensor with flat coils [5]. First experience with pulse excitation of PCB fluxgate was described in [6]. The principal limitation of flat coil design compared to three-dimensional winding is poor magnetic coupling between the flat coils and the core.

Manuscript received March 13, 2006. This work was supported by CTU, National Research Council, Prague, Czech Republic, under Grant 102/05/H032 and by the Ministry of Education, Youth and Sports of the Czech Republic research program under MSM6840770015. The associate editor coordinating the review of this paper and approving it for publication was Dr. Usha Varshney.

J. Kubik waswith the Department of Measurement, Faculty of Electrical Engineering, Czech Technical University, CZ-16627 Praha 6, Czech Republic Technicka 2. He is now with Tyndall National Institute, Cork, Ireland (e-mail: jan.kubikj@centrum.cz; jan.kubik@tyndall.ie).

L. Pavel, P. Ripka, and P. Kašpar are with the Department of Measurement, Faculty of Electrical Engineering, Czech Technical University, CZ-16627 Praha 6, Czech Republic Technicka 2 (e-mail: pavell@email.cz; ripka@fel.cvut.cz; kaspar@fel.cvut.cz)

Digital Object Identifier 10.1109/JSEN.2006.886998

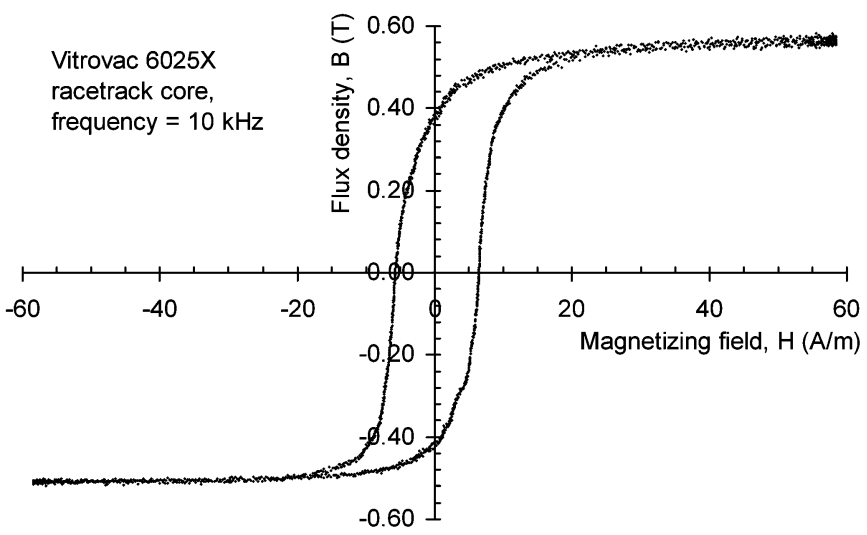

Fig. 1. Vitrovac $6025 \mathrm{X}$ racetrack core B-H loop measured at $10 \mathrm{kHz}$ [6].

The proposed pulse-excited flat fluxgate sensor is intended for use in battery-operated precise navigation devices. The sensor is able to measure geomagnetic field with power consumption lower than $5 \mathrm{~mW}$.

\section{MANUfacturing PROCESS}

The process consists of separate core preparation and then core embedding into the prepared PCB. At first, the racetrackshaped core was etched from $25 \mu \mathrm{m}$ thick Vitrovac $6025 \mathrm{X}$ amorphous alloy sheet. The racetrack core shape was chosen for its high suppression of crossfields and improved sensitivity in longitudinal direction compared to the ringcore shape. The core is $30 \mathrm{~mm}$ long and $8 \mathrm{~mm}$ wide, and the racetrack width is 1.8 $\mathrm{mm}$. The core's B-H loop measured at $10 \mathrm{kHz}$ excitation current showed a coercive force of $6 \mathrm{~A} / \mathrm{m}$ and saturation flux density of $0.54 \mathrm{~T}$ (Fig. 1). Further measurements on the core samples indicated that the initial permeability $\left(\mu_{4}\right)$ was $\sim 26000$, maximum permeability was $\sim 72000$, and maximum differential permeability $\sim 150000$.

The standard four-layer PCB manufacturing technology was used to prepare a sensor frame: three layers of 0.2-mm-thick DURAVER-E-Cu laminate and two layers of 0.065-mm-thick Prepreg solid-state adhesive in between the PCB layers were used. The core-shaped hole was milled into the inner layer of PCB laminate, and the etched core was inserted into this hole before bonding the layers together. Using this design minimizes the transfer of thermal expansion of PCB to the core material [4]. The coils are formed of copper routes on the outer layers of PCB and electroplated through-holes (vias). The sensor has four sections of windings (Fig. 2) to be used as excitation (two round sections, $2 \times 15$ turns, dc resistance $0.43 \Omega$ ), and pickup coils (two straight sections, $2 \times 27$ turns, de resistance $0.64 \Omega$ ). The excitation coils are connected serially, thus totally 30 turns of excitation winding were used. The pickup coils are connected antiserially, forming 27 turns of pickup coil. 


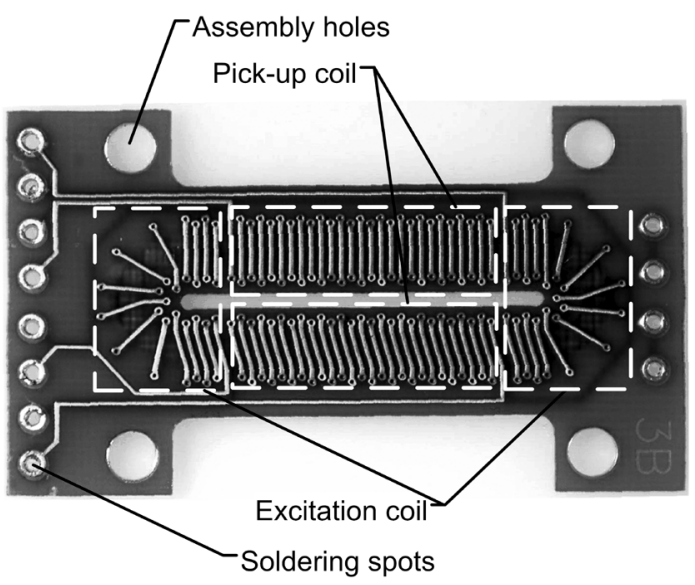

Fig. 2. PCB fluxgate sensor photography [6].

The more detailed description of sensor manufacturing process including cross-section figure of the sensor structure can be found in [4]. The sensor used in further experiments had two layers of embedded core material making the total core thickness $50 \mu \mathrm{m}$ and is referred to as "double-core sensor" in [4].

\section{EXPERIMENT SETUP}

At first, the sensor was excited by an Agilent 33120 generator set to sine wave generation, Krohn-Hite 7500 amplifier, and MT-56 R matching transformer. Then the pulse excitation unit described further on was used. The sensor output was measured by a Stanford Research SR830 lock-in amplifier, and the noise at its output was measured by an Agilent 35670A spectrum analyzer set to $95 \%$ overlap and 50x root mean square averaging. All the measurements were made on the second harmonic frequency. The phase was adjusted for maximum sensitivity at the $50 \mu \mathrm{T}$ field and then kept constant. Six-layer permalloy magnetic shielding with internal thermostat was used to measure noise and offset temperature stability. Helmholtz coils with thermostat was used to measure temperature coefficient of sensitivity. The current waveforms were measured by an Iwatsu CP-502 current probe. The sensor power consumption was calculated using $\mathrm{N}$ voltage $(V(i))$ and current samples $(I(i))$ acquired by Agilent $54624 \mathrm{~A}$ oscilloscope in one excitation period

$$
P=\frac{1}{N} \sum_{i^{\prime}=1}^{N} V(i) I(i) .
$$

In case of pulse excitation (see Section IV), the voltage samples $V(i)$ were calculated as a voltage difference between two probes connected to both ends of the sensor excitation coil in order to avoid short-circuiting one of the excitation bridge branches by oscilloscope probe grounding.

\section{SENSOR EXCITATION}

According to the formulas developed in [7], the amplitude of excitation current to reach maximum sensitivity was calculated to be $160 \mathrm{~mA}$ p-p (presuming triangular excitation current waveform). The dependence of sensitivity on the excitation current is given by the time derivative of the excitation field $\mathrm{dH}_{\mathrm{exc}} / \mathrm{dt}$ in the time interval when the core is not saturated.

First, the sensor was excited by an Agilent generator set to sine wave output and Kron-Hite amplifier to prove the sensor functionality and determine its parameters. The excitation current waveform was not sine wave due to nonlinearity of the inductance of the excitation coil caused by saturation of the core material (an excitation field $\mathrm{B}$ was close to sine wave). The experimentally found excitation current amplitude for maximum sensitivity was $300 \mathrm{~mA} \mathrm{p}$-p in this "B sine wave" excitation mode. The higher optimum $\mathrm{p}-\mathrm{p}$ excitation current than that for theoretical triangular waveform is caused by lower $\mathrm{dH}_{\mathrm{exc}} / \mathrm{dt}$ of the "B sine wave" excitation mode in the time interval when the core is not saturated. The sensor has maximum sensitivity at $200 \mathrm{kHz}$, but sensitivity itself is not the most important parameter. We have shown in [4] that at lower excitation frequency ( 5 or $10 \mathrm{kHz}$ for this sensor design), lower sensor noise and better temperature stability can be achieved. The sensitivities of the sensor at these frequencies were 116 and $241 \mathrm{~V} / \mathrm{T}$ for 5 and $10 \mathrm{kHz}$, respectively, measured for "B sine wave" excitation mode with $300 \mathrm{~mA}$ p-p current. The power efficiency of sine wave excitation is not optimal unless excitation tuning by parallel capacitor is used. Such tuning by parallel capacitor was not possible in case of a PCB fluxgate sensor, which has high winding resistance causing low Q-factor of the LC resonant circuit.

The previous works on fluxgate sensor with electrodeposited core and wire wound pickup coil [8] have shown that the pulse excitation can significantly reduce the power consumption. The pulse excitation circuit with variable duty cycle was designed to investigate the properties of bipolar pulse excitation applied to PCB fluxgate sensor. The pulse excitation circuit is based on 2 IRF7103 HEXFET transistors creating a full $\mathrm{H}$-bridge and 2 ADP3412 MOSFET drivers (Fig. 3). The control part of the excitation unit is based on Complex Programmable Logic Device (CPLD) Altera 3064A producing the transistor-transistor logic driving signals RIGHT and LEFT and also second harmonic square wave reference signal for the lock-in amplifier. These signals are derived from the CPLD input clock signal by frequency division. The RIGHT and LEFT signals are the driving signals for MOSFET drivers; the pulse duration $t$ of these signals determines the duration of fluxgate excitation current pulses. The mutual phase-shift of these signals is set to $180^{\circ}$ in order to achieve excitation current pulses containing only odd harmonic components. Using external clock instead of fixed crystal oscillator is a flexible solution allowing us to change the excitation frequency simply by changing input clock frequency of the CPLD. The CPLD accepts clock frequency up to $222 \mathrm{MHz}$, and this corresponds to a maximum excitation frequency of $1.7 \mathrm{MHz}$. The duty cycle $t / T$ can be adjusted in steps $(1.56,3.13,6.25,12.5,25$, and $50 \%)$ by DIP switches on the control part of the excitation circuitry. Fig. 4 demonstrates the sharp peaks of the excitation current of $300 \mathrm{~mA} \mathrm{p}-\mathrm{p}$ while the root mean square (rms) value is kept down at $24 \mathrm{~mA}$. The same figure shows the induced voltage waveforms for the measured field of 0 and $38 \mu \mathrm{T}$. 

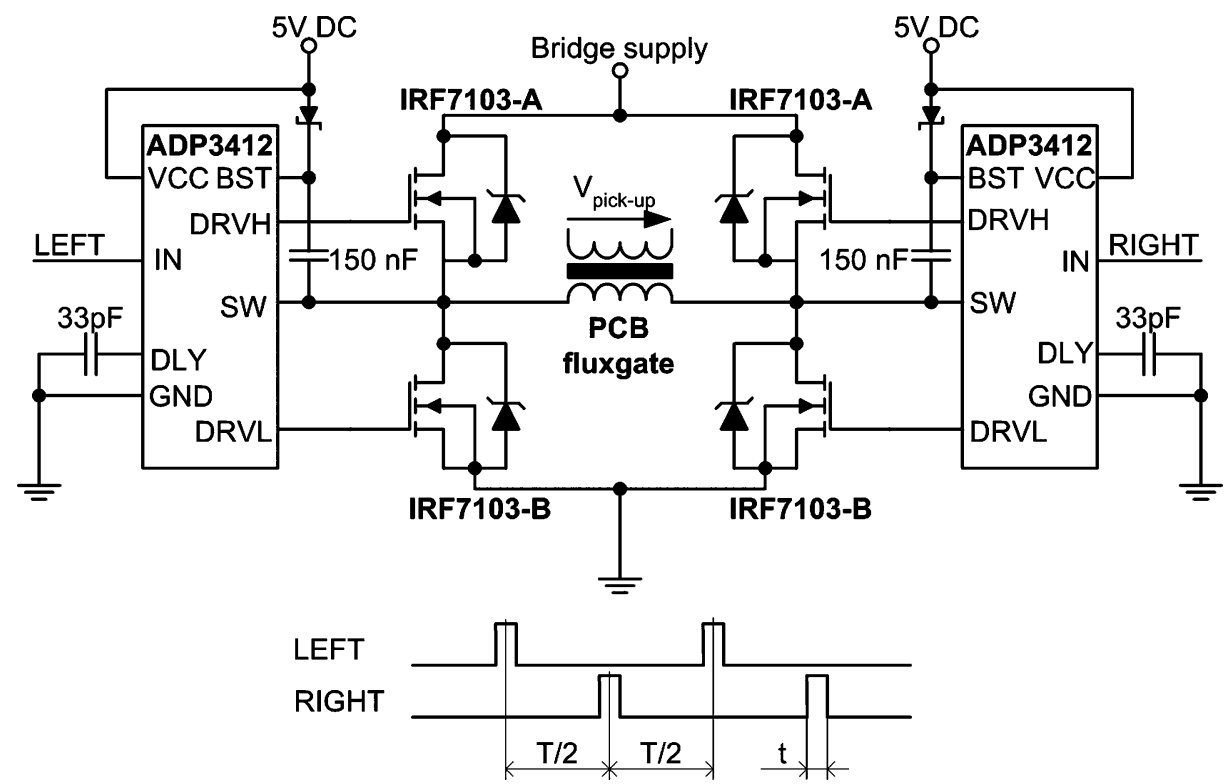

Fig. 3. Power part of the fluxgate sensor excitation circuitry including the HEXFET H-bridge.

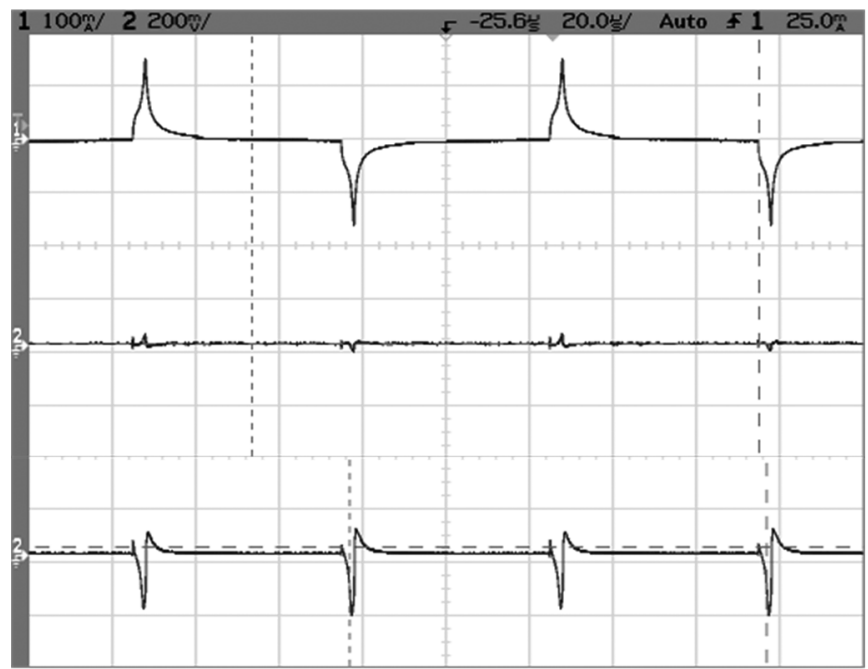

Fig. 4. PCB fluxgate excitation current $300 \mathrm{~mA} \mathrm{p}$-p, frequency $10 \mathrm{kHz}$, duty factor of $6.25 \%$ (top trace, $100 \mathrm{~mA} / \mathrm{div}$ ), and sensor response to measured field 0 (middle trace, $200 \mathrm{mV} / \mathrm{div}$ ) and $38 \mu \mathrm{T}$ (bottom trace, $200 \mathrm{mV} / \mathrm{div}$ ).

\section{MEASURED RESUlts}

\section{A. Power Consumption}

Theoretically, the excitation power is increasing with frequency due to the frequency dependence of hysteresis and eddy current losses. However, in most cases (excluding the excitation current of $100 \mathrm{~mA}$ ), we observed that the power consumption at $10 \mathrm{kHz}$ excitation frequency was lower than for $5 \mathrm{kHz}$ excitation frequency (Fig. 5). This is favorable due to higher sensitivity of the sensor at $10 \mathrm{kHz}$ excitation frequency. Similar complex nonlinear behavior in frequency was observed in fluxgate sensors with tuned excitation [10].

The power consumption naturally increased with increasing duty cycle. The power consumption of the sensor including the bridge for sufficient excitation current of $300 \mathrm{~mA} \mathrm{p}-\mathrm{p}, 10 \mathrm{kHz}$

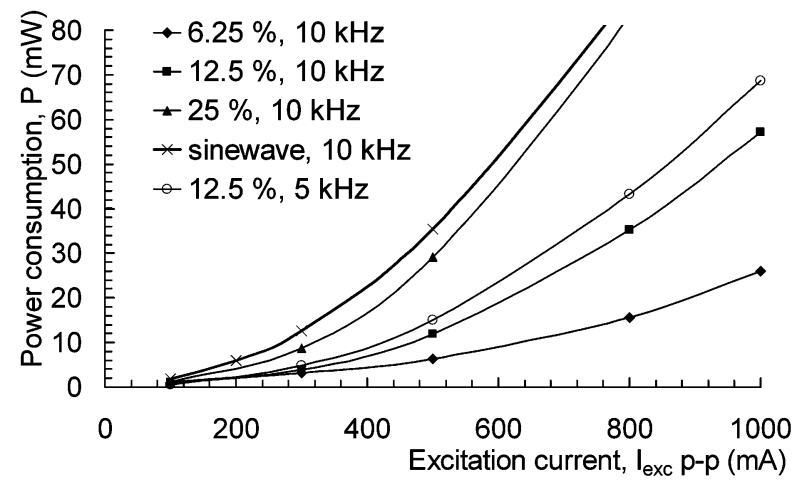

Fig. 5. Power consumption of PCB fluxgate (duty factor of excitation current in percent and excitation frequency are denoted) [6].

reached $3.1 \mathrm{~mW}$ (6.25\% duty cycle), $3.9 \mathrm{~mW}(12.5 \%)$, and 8.8 $\mathrm{mW}(25 \%)$. The bridge voltage was in the range of $0.76-0.38$ $\mathrm{V}$, and the rectified mean current values were in the range of 4-23 mA. It was not effective to use shorter pulses due to highly increasing bridge voltage and instability of excitation current p-p values in such cases.

\section{B. Sensitivity}

The sensor full scale linear range was $\pm 100 \mu \mathrm{T}$. The maximum sensitivity of $241 \mathrm{~V} / \mathrm{T}$ reached for "B sine wave" excitation was for the $300 \mathrm{~mA} \mathrm{p}-\mathrm{p}$ excitation current (Fig. 6). The pulse excitation behavior is different: the sensitivity is slowly increasing even up to $1000 \mathrm{~mA}$ p-p. The sensitivity is also increasing with increase in the duty cycle of the excitation current. Generally, the sensitivity of a pulse excited sensor is lower than that of a "B sine wave" excited sensor for lower excitation currents below $500 \mathrm{~mA}$ p-p. The sensitivity of the pulse excited sensor reached $94 \mathrm{~V} / \mathrm{T}$ for $300 \mathrm{~mA}$ p-p current at $10 \mathrm{kHz}$ with $12.5 \%$ duty cycle. The sensor pickup coil tuning did not bring any increase of sensitivity due to low Q-factor of the pickup coil. 


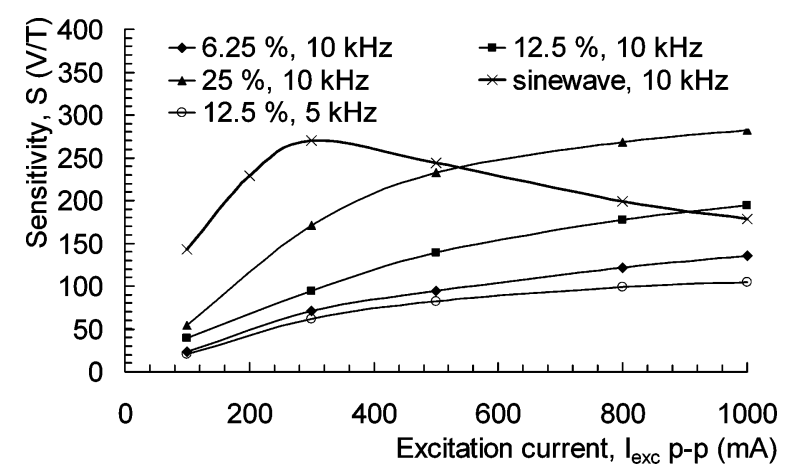

Fig. 6. Sensitivity of PCB fluxgate [6].

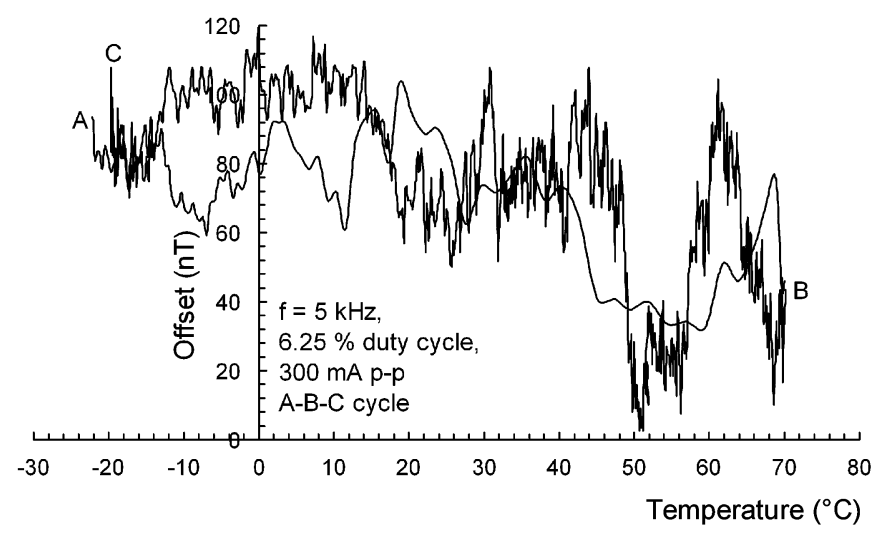

Fig. 7. Offset temperature stability of pulse excited PCB fluxgate sensor [6].

\section{Temperature Stability}

The offset temperature stability has degraded when using pulse excitation. The "B sine wave" excited (300 mA p-p, 5 $\mathrm{kHz}$ ) sensor had offset drift in the -20 to $+70{ }^{\circ} \mathrm{C}$ temperature range below $16 \mathrm{nT}$. The same value for a pulse excited $(5 \mathrm{kHz}$, $300 \mathrm{~mA} \mathrm{p}-\mathrm{p}, 6.25 \%$ duty factor) sensor was $120 \mathrm{nT}$ (Fig. 7), which is 7.5 times worse than for the same p-p "B sine wave" excitation current. The $120 \mathrm{nT}$ offset temperature drift is still more than 40 times lower than values reported for an electrodeposited core [11]. On the other hand, the temperature coefficient of sensitivity was not affected by pulse excitation. We even observed a slight improvement of the sensitivity tempco from $0.25 \% /{ }^{\circ} \mathrm{C}$ when using sine wave excitation to $0.17 \% /{ }^{\circ} \mathrm{C}$ when using pulse excitation. (Fig. 8).

\section{Noise}

The sensor noise increased when using pulse excitation. The noise power spectrum density at $1 \mathrm{~Hz}$ was 24 and 710 $\mathrm{pT}_{\mathrm{rms}} / \sqrt{ } \mathrm{Hz}$ for "B sine wave" mode (300 mA p-p, $\left.10 \mathrm{kHz}\right)$ and pulse excitation (300 mA p-p, $10 \mathrm{kHz}, 6.25 \%$ duty cycle), respectively. The noise rms value in the range from $64 \mathrm{mHz}$ to $10 \mathrm{~Hz}$ was 0.7 and $3.7 \mathrm{nT}_{\mathrm{rms}}$ for "B sine wave" and pulse excitation. The noise increase for pulse excitation was also observed in [8]. The noise is considerably higher than when using the same sensor with wire wound pickup coil, which could be effectively tuned and noise greatly reduced [9]. However, the achieved noise level is still lower compared to anisotropic

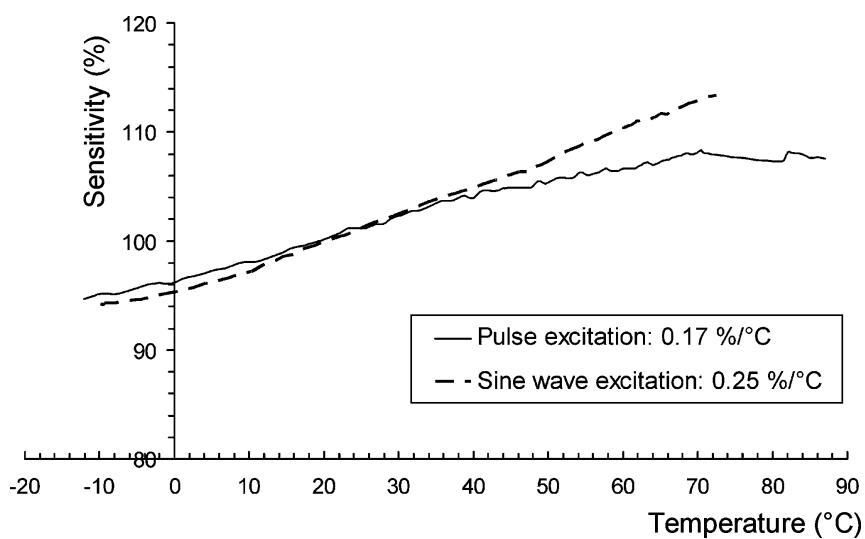

Fig. 8. Sensitivity temperature stability of pulse and sine wave excited PCB fluxgate sensor.

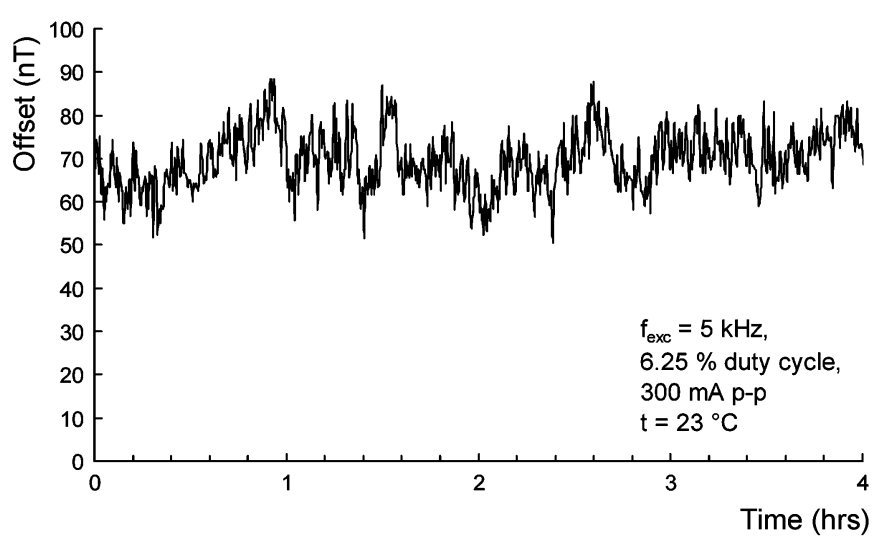

Fig. 9. Offset time stability of the pulse excited PCB fluxgate sensor offset.

magnetoresistance (AMR) sensors and sufficiently low for our application, which is precise compass.

\section{E. Offset Short-Time Stability}

The short-time stability of the sensor offset (or the ultra-low-frequency noise) was measured within $3 \mathrm{~h}$ by sampling the sensor output every $20 \mathrm{~s}$. The p-p offset value remained within $38 \mathrm{nT}$ range (Fig. 9) when using $5 \mathrm{kHz}$ excitation current with $6.25 \%$ duty cycle and $300 \mathrm{~mA} \mathrm{p}$-p current. This value is significantly worse than $3.5 \mathrm{nT}$ when using " $\mathrm{B}$ sine wave" excitation at $5 \mathrm{kHz}$ [4] but still acceptable for many precise applications.

\section{F. Perming}

The perming effect (permanent offset change after the applied field shock disappears) was a great concern when "sine wave" excitation showed perming effect of $\sim 5 \mu \mathrm{T}$ after a field shock of $10 \mathrm{mT}$. However, the pulse excitation mode fluxgate appeared to be more resistant to the field shocks: the $10 \mathrm{mT}$ field shock caused only below $1.2 \mu \mathrm{T}$ offset change when using $10 \mathrm{kHz}$, $300 \mathrm{~mA}$ p-p, $6.25 \%$ duty cycle excitation.

\section{CONCLUSIONS}

The results clearly show that power consumption lower than $5 \mathrm{~mW}$ can be achieved even for $300 \mathrm{~mA}$ p-p excitation current (duty cycle $\mathrm{d}=6.25 \%$ or $12.5 \%$, with frequency of either 5 or 
$10 \mathrm{kHz}$ ), whereas the "sine wave" excitation consumes $\sim 13 \mathrm{~mW}$ for 5 or $10 \mathrm{kHz}$ excitation frequency for the same p-p current value. The bridge supply voltage is $0.76 \mathrm{~V}$ for $10 \mathrm{kHz}, 6.25 \%$ duty cycle and $0.47 \mathrm{~V}$ for $10 \mathrm{kHz}, 12.5 \%$ duty cycle, which is low enough for battery-operated devices. This would allow excitation of three serially connected orthogonal sensors using a single supply voltage.

The power efficiency of pulse excitation is even more increasing with increased current amplitude. For example, 500 $\mathrm{mA}$ p-p excitation current at $10 \mathrm{kHz}$ requires $35 \mathrm{~mW}$ when using "B sine wave" excitation mode but only $6.2 \mathrm{~mW}$ when using pulse excitation with duty cycle $6.25 \%$.

The power consumption of only $2 \mathrm{~mW}$ was achieved for 300 mA p-p excitation current with $6.25 \%$ duty cycle at $5 \mathrm{kHz}$ with sensitivity of $36 \mathrm{~V} / \mathrm{T}$.

The offset temperature stability was within $120 \mathrm{nT}$ and sensitivity tempco was $0.17 \%{ }^{\circ} \mathrm{C}$ in the -20 to $+70{ }^{\circ} \mathrm{C}$ temperature range. The sensor noise was $710 \mathrm{pT}_{\mathrm{rms}} / \sqrt{ } \mathrm{Hz}$ at $1 \mathrm{~Hz}$. The sensor offset short-time stability was $38 \mathrm{nT}$ within $3 \mathrm{~h}$. The sensor perming error substantially improved to $\sim 1.2 \mu \mathrm{T}$ for 10 $\mathrm{mT}$ shock when pulse excitation was used.

Generally, the pulse excitation degraded the noise properties, temperature, and time stability of the sensor offset. However, the tempco of sensitivity was not affected by pulse excitation, and perming error was even four times decreased. Thus the developed sensor is more precise and less energy-consuming than a periodically flipped AMR sensor. The achieved parameters are sufficient for compass with $0.1^{\circ}$ error.

We believe that more even distribution of excitation winding around all core length could further improve the perming error and noise due to better magnetization of the sensor core. This will be investigated in the next sensor prototype. Future research will also include investigation of alternative signal extraction method optimized for pulse excited sensor to decrease the noise values and increase the sensor offset stability.

\section{ACKNOWLEDGMENT}

The core material was kindly supplied by Vacuumschmelze (www.vacuumschmelze.de). The sensor samples were manufactured by Pragoboard (www.pragoboard.cz).

\section{REFERENCES}

[1] O. Dezuari, E. Belloy, S. E. Gilbert, and M. A. M. Gijs, "Printed circuit board integrated fluxgate sensor," Sens. Actuators A, vol. 81, pp. 200-203, 2000.

[2] L. Perez, C. Aroca, P. Sánchez, A. López, and M. C. Sánchez, "Planar fluxgate sensor with an electrodeposited amorphous core," Sens. Actuators A, vol. 109, no. 3, pp. 208-211, 2004.

[3] H.-S. Park, J.-S. Hwang, W.-Y. Choi, D.-S. Shima, K.-W. Naa, and S.-O. Choi, "Development of micro-fluxgate sensors with electroplated magnetic cores for electronic compass," Sens. Actuators A, vol. 114, no. 2-3, pp. 224-229, 2004.

[4] J. Kubík, L. Pavel, and P. Ripka, "PCB racetrack fluxgate sensor with improved temperature stability," Sens. Actuators A, vol. 130-131, pp. 184-188, 2006.

[5] P. Kejík, B. Chiesi, R. S. Janossy, and Popovic, "A new compact 2D planar fluxgate sensor with amorphous metal core," Sens. Actuators A, vol. 81, pp. 180-183, 2000.

[6] J. Kubík, L. Pavel, P. Ripka, and P. Kašpar, "Low-power PCB fluxgate sensor," in Proc. IEEE Sensors 2005, Irvine, CA, 2005, pp. 432-435.
[7] O. V. Nielsen, J. R. Petersen, A. Fernandez, B. Hernando, P. Spisak, F Primdahl, and N. Moser, "Analysis of a fluxgate magnetometer based on metallic glass sensors," Meas. Sci. Technol., vol. 2, pp. 435-440, 1991.

[8] A. Tipek, T. O’Donnel, P. Ripka, and J. Kubik, "Excitation of PCB fluxgate sensor," in Proc. IEEE SENSORS 2003, Toronto, ON, Canada, 2003, pp. 647-650.

[9] J. Kubík and P. Ripka, "Noise spectrum of pulse excited PCB fluxgate sensor," Sens. Actuators A, vol. 132, no. 1, pp. 236-240, 2006.

[10] P. Ripka and W. G. Hurley, "Excitation efficiency of fluxgate sensors," Sens. Actuators A, vol. 129, no. 1, 2, pp. 75-79, 2006.

[11] T. Tipek and P. O'Donnel, "Excitation and temperature stability of PCB fluxgate sensor," IEEE Sensors J., vol. 5, no. 6, pp. 1264-1269, 2005.

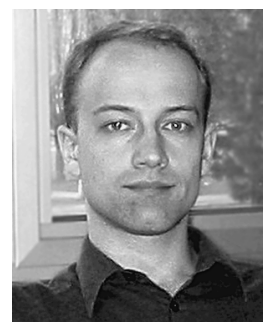

Jan Kubík received the Ing. (M.Sc.) degree from Czech Technical University, Prague, Czech Republic, in 2003, where he is currently pursuing the Ph.D. degree in the Faculty of Electrical Engineering.

The subject of his dissertation is PCB fluxgate sensors. His research interests range from PCB fluxgate sensors design and characterization to measurement systems development and magnetism finite-element method modelling. He is the main author of a recently submitted provisional patent. He is author or coauthor of six journal papers and 12 conference papers.

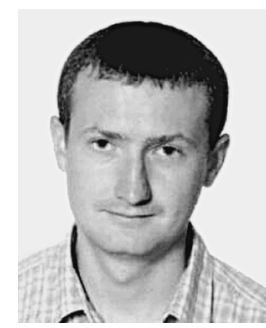

Lukáš Pavel received the Ing. (M.Sc.) degree from Czech Technical University, Prague, Czech Republic, in 2005

His master's thesis was on development and characterization of PCB fluxgate sensors. His research interests included fluxgate sensors and measurement systems development. He is now with SkodaAuto, a.s. as Software Technical Support of Production.

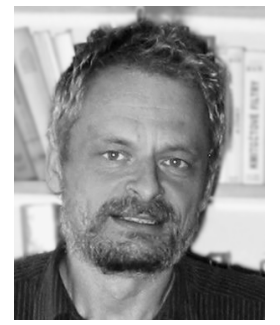

Pavel Ripka (M'00) received the Ing. (M.Sc.), CSc degree (Ph.D.), and Prof. degrees from Czech Technical University, Prague, Czech Republic, in 1984, 1989, and 2001, respectively.

$\mathrm{He}$ is a Professor with the Department of Measurement, Faculty of Electrical Engineering, Czech Technical University, teaching courses in "Electrical Measurements and Instrumentation" and "Engineering Magnetism and Sensors." His main research interests are magnetic measurements and magnetic sensors, especially fluxgate. He is the author of more than 120 papers and has received five patents. He is a member of the Eurosensors Steering Committee and was a General Chairman of the Eurosensors 2002 conference.

Prof. Ripka is a member of the Elektra society, the Czech Metrological Society, and the Czech National IMEKO Committee. He was an Associate Editor of the IEEE SENSORS JOURNAL.

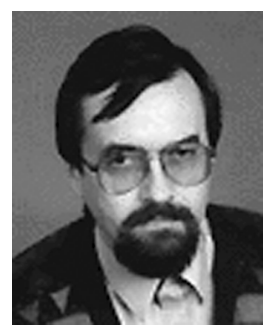

Petr Kašpar was born in Prague, Czechoslovakia, in 1955. He received the Ing. (M.Sc.) in 1981 and CSc (Ph.D.) from Czech Technical University, Prague, in 1981 and 1988, respectively.

Since 1999, he has been an Associate Professor in the Laboratory of Magnetic Measurements, Faculty of Electrical Engineering, Czech Technical University. His research interests include PC controlled systems for magnetic measurements, measurements of magnetic disturbances, and test of magnetic materials. 